\title{
Aransemen Paduan Suara Musafir Isfanhari: Personal Taste atau Kepatuhan Konsep Bermusik?
}

\author{
Eko Salaludin Aziz \\ Program Studi Desain Komunikasi Visual, Fakultas Teknologi dan Informatika, Universitas \\ Dinamika Surabaya \\ Email: ekosa@dinamika.ac.id
}

\begin{abstract}
This study discusses the figure of Musafir Isfanhari who has a high dedication, both as an educator and as a practitioner (especially as an arranger) in music aspect in East Java. The focus of this research is about Isfanhari's arrangement. To discuss and analyze the works of Isfanhari in this study, musical arrangements theory is used (to analyze the choral arrangements made by Isfanhari). The study applied a qualitative approach with a musicology approach. This approach is useful for dissecting the works of Musafir Isfanhari's arrangement, not only in terms of the standard rules of harmony and arrangement, but also in terms of Isfanhari's personal aesthetics as a musician. The results showed that Isfanhari works as a choir composer. The arrangement of works produced was not only used at the school level, but also used as material for the Gita Bahana Nusantara Choir song for the Republic of Indonesia's independence ceremony at the Istana Negara. Based on these results, it can be concluded that Musafir Isfanhari is able to become a musical figure who has a positive influence in East Java. Not only his arrangement, but also his ideas can bring significant developments to music aspect in East Java.
\end{abstract}

Key Words: Musafir Isfanhari, arranger, choir.

\begin{abstract}
Abstrak: Penelitian ini membahas tentang ketokohan Musafir Isfanhari yang memiliki dedikasi tinggi, baik sebagai pendidik maupun sebagai praktisi (khususnya sebagai arranger) dalam dunia seni musik di Jawa Timur. Fokus penelitian ini yaitu mengenai kekaryaan aransemen Isfanhari. Untuk membahas dan menganalisis karya aransemen Isfanhari dalam penelitian ini, digunakan teori aransemen musik (untuk menganalisis karya aransemen paduan suara yang digarap Isfanhari). Penelitian menerapkan pendekatan kualitatif dengan pendekatan musikologi. Pendekatan ini berguna untuk membedah karya aransemen Musafir Isfanhari, tidak hanya dipandang dari sisi aturan baku harmoni dan aransemen, tetapi juga dari sisi estetika pribadi Isfanhari sebagai seorang musisi. Hasil penelitian menunjukkan bahwa Isfanhari berprofesi sebagai penggubah musik paduan suara. Karya-karya aransemen yang dihasilkan tidak hanya digunakan pada tingkat sekolah saja, tetapi juga digunakan sebagai materi lagu Paduan Suara Gita Bahana Nusantara untuk upacara kemerdekaan Republik Indonesia di istana negara. Berdasarkan hasil penelitian tersebut, dapat disimpulkan bahwa Musafir Isfanhari mampu menjadi seorang tokoh musik yang memiliki pengaruh positif di Jawa Timur. Tidak hanya karya aransemennya, tetapi juga buah-buah pikirannya dapat membawa perkembangan yang signifikan bagi Seni Musik di Jawa Timur.
\end{abstract}

Kata-kata Kunci: Musafir Isfanhari, arranger, paduan suara.

\section{PENDAHULUAN}

Musafir Isfanhari, adalah salah satu tokoh yang memiliki peran besar dalam perkembangan seni musik di Indonesia, khususnya paduan suara di Jawa Timur. Hingga saat ini, Isfanhari telah menggubah puluhan lagu dari beragam genre dan dikemas dalam format paduan suara. Hal yang menjadikan karya aransemen Isfanhari memiliki nilai fungsi yang tinggi adalah karya-karyanya tidak semata-mata ditujukan untuk kepentingan komersial, namun Isfanhari justru lebih mengutamakan lingkup pendidikan sebagai 'pengguna' karya aransemen lagunya. Sebagai contoh, dua dari sejumlah karya aransemen Isfanhari yang dianggap paling berkesan bagi beliau adalah lagu "Bukit Kemenangan" dan lagu "Seuntai Manikam". Berkesan karena ketika menggarap kedua lagu tersebut, Isfanhari melakukannya atas dasar 'panggilan hati' sebagai seorang musisi dan ketertarikan akan 
alur melodi utama dari lagu tersebut, bukan atas dasar pesanan atau garapan komersial yang harus diselesaikan beliau dari pihak tertentu. Dengan hasil aransemen yang grande dan memukau, aransemen paduan suara lagu "Bukit Kemenangan" dan "Seuntai Manikam" yang telah rampung digarap Musafir Isfanhari justru pada akhirnya digunakan secara resmi oleh Paduan Suara Gita Bahana Nusantara pada saat upacara kemerdekaan Republik Indonesia.

Republik Indonesia adalah negara yang memiliki begitu banyak kekayaan, mulai dari kekayaan alam hingga kekayaan budaya. Beragam suku, adat istiadat, bahasa, dan juga kesenian terhampar dengan begitu variatif di segala penjuru Negara Indonesia, mulai dari Sabang hingga ke Merauke. Sudah menjadi tanggung jawab dari warganegara Indonesia untuk turut menjaga kelestarian alam dan budaya yang ada di negeri tercinta ini. Salah satu kekayaan Indonesia yang menjadi sorotan dewasa ini adalah kekayaan seni musiknya. Terdapat banyak jenis musik daerah atau musik tradisional di Indonesia. Generasi muda, yang identik sebagai peminat dan pelaku aktif seni musik, seharusnya mampu mengenal dengan baik jenis-jenis musik yang ada di Indonesia. Namun sayangnya, masyarakat muda Indonesia lebih 'fasih' dalam menyanyikan lagu-lagu yang berasal dari luar tanah airnya, umpama terseret tanpa kendali dalam arus globalisasi. Mereka tidak mengenal, bahkan tidak mengetahui beragam jenis musik dan lagulagu daerah di Indonesia yang diwariskan secara turun-temurun oleh nenek moyang.

Melihat keprihatinan tersebut, dibutuhkan munculnya seorang sosok yang mampu menghidupkan kembali seni musik dan lagu asli Indonesia di dalam lingkup masyarakatnya, sejak dini. Salah satu cara mewujudkan hal tersebut adalah dengan mendekatkan seni musik secara bertahap dan kontinyu ke dalam ranah pendidikan anakanak di sekolah.

Peran andil aransemen musik Isfanhari dalam dunia pendidikan pada mulanya berangkat dari kepedulian dan kecintaannya terhadap anak-anak. Dalam sudut pandang Isfanhari, sangatlah perlu dan penting bagi anak-anak untuk dikenalkan dengan dunia musik sejak dini, karena melalui seni musik, anak-anak dapat mengenal dan mempelajari segala aspek kehidupan secara mudah dan menyenangkan. Pendapat ini dibuktikan dengan lagu-lagu hasil ciptaannya yang bersifat tematik, mulai dari tema binatang, alat transportasi, permainan, hingga aktivitas kehidupan sehari-hari, di mana karya-karya tersebut bertujuan untuk memperkenalkan anak-anak pada lingkungan sosialnya melalui musik (bernyanyi).

Tidak hanya itu, Isfanhari juga mengaransemen lagu-lagu yang bertema nasional dan kedaerahan. Tujuannya adalah agar karya tersebut dapat digunakan dalam wilayah pembelajaran Seni Musik di sekolah. Berdasarkan hasil wawancara, diungkapkan bahwa Isfanhari memiliki kekhawatiran terhadap tumbuh kembang anak pada usia sekolah di mana mereka sudah mulai terkena efek negatif dari arus globalisasi, salah satu contohnya adalah mulai melupakan atau bahkan tidak mengenal kebudayaan bangsanya sendiri. Sedikit sekali anak-anak sekolah pada dewasa ini yang mengetahui dan dapat menyanyikan lagu-lagu nasional atau lagu daerah. Hal itu terjadi salah satunya karena lagu nasional atau lagu daerah jarang diajarkan kepada anak-anak selama mereka duduk di bangku sekolah. Oleh karena itulah, melalui karya-karya aransemennya, Isfanhari berupaya untuk mendekatkan kembali anakanak sekolah kepada kebudayaan bangsanya sendiri, bangsa Indonesia.

Sesuai dengan namanya, 'Musafir' yang berarti pengembara, kepedulian Isfanhari terhadap Seni Musik dalam dunia pendidikan juga 'mengembara' dan mengukuhkannya sebagai pendidik musik hingga ke jenjang perguruan tinggi. Dalam kesehariannya, Isfanhari juga bekerja sebagai dosen di Jurusan Sendratasik (konsentrasi musik) dan Program Studi Seni Musik, Fakultas Bahasa dan Seni, Universitas Negeri Surabaya. Sebagai dosen, Isfanhari 'mewariskan' ilmu dan kemampuannya dalam mengaransemen suatu lagu agar kelak nantinya akan muncul generasi-generasi baru yang mampu meneruskan cita-cita mulia Isfanhari dalam mengembangkan seni musik, khususnya musik paduan suara, di Jawa Timur. 
Berdasarkan latar belakang yang telah dipaparkan di atas, maka penulis tertarik untuk mengangkat Musafir Isfanhari sebagai tokoh yang memiliki dedikasi tinggi, khususnya sebagai arranger dalam dunia seni musik di Jawa Timur. Hal-hal yang menjadi dasar pertimbangan penulis untuk menjadikan Isfanhari sebagai tokoh yang dibahas dalam penelitian ini antara lain: (1) Sebagai seorang lulusan akademi musik, Isfanhari telah membuktikan keberhasilan dalam bidangnya. Isfanhari telah memperoleh berbagai penghargaan dalam bidang musik dari Dinas Kotamadya, propinsi, hingga level nasional; (2) Isfanhari memiliki banyak karya yang abadi dan dapat digunakan oleh generasi selanjutnya. Ini dibuktikan pada gubahan lagu-lagu Isfanhari yang menjadi materi pokok dalam pembelajaran Seni Musik di sekolah-sekolah; (3) Selain itu, Isfanhari juga memiliki pengaruh penting dalam masyarakat. Isfanhari kerap menjadi juri dalam festivalfestival musik tidak hanya dalam wilayah Jawa Timur, tetapi hingga tingkat regional dan nasional. Ini menunjukkan bahwa Isfanhari memiliki kualitas (pengetahuan, kecakapan, dan kharisma) pribadi yang khas yang dapat dijadikan panutan serta hasil pemikirannya dapat dipercaya oleh orang lain (Sztompka,2007:305-306).

\section{KAJIAN PUSTAKA}

Seni Musik

Sebagian ahli berpendapat bahwa musik timbul dari kehidupan manusia di dalam mencurahkan ekspresinya dengan menirukan bunyi-bunyi binatang. Sebagian lagi berpendapat bahwa musik berasal dari bahasa manusia sehari-hari. Pada umumnya, para ahli sependapat bahwa perkataan musik berasal dari Bahasa Yunani "mousike", yang berasal dari kata mouse atau mouskos, yang merupakan salah seorang dewa atau dewi dalam mitologi bangsa Yunani kuno, yang menguasai cabang kesenian dan ilmu pengetahuan. Dalam bahasa Latin, dikenal dengan sebutan musica yang berasal dari kata musa, yang mempunyai pengertian yang sama seperti dalam bahasa Yunani (Departemen Pendidikan dan Kebudayaan,1982:1).

Terdapat beberapa definisi musik menurut para ahli: (1) Menurut Aristoteles, musik merupakan salah satu wadah seseorang untuk mengungkapkan ide tertentu sehingga dapat mendamaikan hati yang gundah serta dapat memberikan terapi rekreatif.; (2) Musik adalah keindahan suara yang dapat didengar. Sumber suara ini dua macam asalnya, yang dihasilkan oleh alatalat dan yang dihasilkan oleh manusia. Suara yang dihasilkan oleh alat-alat disebut instrumental dan suara yang dihasilkan oleh manusia disebut vokal. Musik, baik vokal maupun instrumental, terdiri atas empat unsur yaitu melodi, harmoni, irama (ritme) dan timbre (warna suara) (Simanungkalit, 2008:1); (3) Musik adalah cabang seni yang membahas dan menetapkan berbagai suara ke dalam pola - pola yang dapat dimengerti dan dipahami manusia (Banoe, 2003:288); (4) Djohan menyatakan, musik adalah sesuatu yang tak tampak, tetapi kita tahu ia ada. Tidak dapat disentuh, tetapi dapat dimainkan. Tidak dapat dirasa, tetapi dapat mengesankan, tidak dapat dibau sebelum ia mengisi udara dengan keharuman. Karena musik adalah cara Tuhan dalam mewarnai udara. (Djohan, 2010:1); serta (5) Musik adalah suatu hasil karya seni bumi dalam bentuk lagu atau komposisi musik, yang mengungkapkan pikiran, perasaan dari penciptanya melalui unsurunsur musik yaitu irama, melodi, harmoni, bentuk atau struktur lagu, dan ekspresi sebagai satu kesatuan (Jamalus, 1988:1).

Setelah mengetahui pendapatpendapat dari para ahli tersebut, dapat disimpulkan bahwa musik adalah ungkapan jiwa manusia yang diekspresikan melalui bunyi atau nada-nada indah yang di dalamnya terkandung unsur-unsur musik yaitu ritme, harmoni, irama, melodi sebagai satu kesatuan yang utuh dan memiliki maksud tertentu.

\section{Aransemen}

Aransemen berasal dari bahasa Belanda "Arrangement", yang artinya penyesuaian komposisi musik dengan nomor suara penyanyi atau instrumen musik yang didasarkan atas sebuah komposisi yang telah ada sehingga esensi musiknya tidak berubah. Orang yang melakukan aransmen lagu dikenal dengan sebutan Arranger atau pengaransemen. Modal dasar yang harus dimiliki oleh seorang arranger adalah menguasai pengetahuan tentang harmoni. (https://mgmpseni.wordpress.com/materi- 
belajar/seni-musik/semester-1/kelasviii/aransemen-musik/). Terdapat tiga jenis aransemen, antara lain sebagai berikut:

\section{Aransemen Vokal.}

Setiap lagu dapat disusun aransmen khusus vokal, yaitu dalam dua suara, tiga suara, empat suara. Untuk menyusun aransemen vokal, yang paling mudah adalah menyusun aransemen lagu dalam dua suara, karena untuk menyusun aransmen lagu dalam tiga dan empat suara ada banyak persyaratan yang harus diperhatikan.

Untuk memperoleh hasil yang lebih baik dan memuaskan, setelah selesai disusun aransemen lagunya kemudian dicoba untuk dinyanyikan secara bersama-sama. Apabila dirasa kurang baik atau kurang memuaskan maka dapat dicoba lagi untuk menyusun aransmen lagu tersebut hingga pada akhirnya diperoleh hasil yang sangat memuaskan.

Dalam membuat arransemen paduan suara, perlu diketahui dan dijaga wilayah atau batas suara manusia dari empat jenis suara manusia yaitu: Sopran, Alto, Tenor, Bass (SATB). Edmud (2009:95) menyatakan bahwa, "Arransemen yang mempergunakan suara pria maupun wanita disebut arransemen untuk 'koor campuran'. Susunan inilah sejak dahulu dianggap yang paling sempurna. Wilayah suara yang dapat dipakai cukup luas sehingga setiap suara dapat memperlihatkan semua register suara. Inilah pentingnya khusus untuk arransemen polifon, di mana kadang-kadang perlu menonjolkan satu suara diantara yang lainnya".

Dalam menyusun arransemen paduan suara, perlu lah mengetahui empat suara yang nyata, artinya harus menyusun empat suara pada lagu secara bersama-sama untuk mengungkapkan langkah-langkah harmonis; dan janganlah hanya dilihat yang terakhir saja, yakni kesesuaian antar nada secara vertikal.

Berikut langkah-langkah menurut Edmud (2009:95) dalam menyusun arransemen paduan suara untuk Koor Campuran yaitu:

a. Nyanyikanlah lagu beserta syair dan carilah kesan mana diungkapkan dalam nada dan kata.

b. Nyanyikan lagu dan perhatikanlah tempo, kesatuan hitungan, buat tanda letak penggalan setengah kalimat dan akhir kalimat lagu, serta letak bunyi nada terendah dan nada tertinggi.

c. Carilah akord untuk setiap kesatuan hitungan, misalnya dalam birama $4 / 4$ untuk setiap pukulan kesatu dan ketiga bila temponya sedang. Untuk pukulan ke 1 ke 2 ke 3 ke 4 bila tempo lagu sungguh lambat. Begitu pula untuk jenis irama yang lainnya. Perhatikanlah bahwa irama dan hitungan berjalan terus bila sebuah nada melodi ditahan atau beristirahat. Ini berarti akordnya harus berubah atau diterapkan Vorhalt atau nada peralihan. Namun berhati-hatilah dalam menjembatani penggalan, agar tidak ada kesukaran untuk mengambil nafas.

d. Buatlah lagu bass atau suara bawah dengan:

1) Memperhatikan akord-akord yang telah ditandai.

2) Mengembangkan kode yang sudah ditulis, misalnya dengan membalikkan akord atau menggantinya dengan akord pembantu.

3) Membuat lagu bass yang berlawanan dengan melodi.

4) Mengusahakan agar lagu bass menjadi diatonik, misalnya dengan menggunakan nada peralihan, di mana ada lompatan, kecuali dalam kadens.

5) Menjaga agar irama bass tidak selalu sama dengan irama melodi, khususnya di mana melodi mendapat nada yang diperpanjang (bass harus memperdengarkan kesatuan hitungan).

6) Memakai lompatan terts dalam bass bila akord yang sama diulang, dengan memakai second untuk masuk dalam akord baru (namun ini tidak berlaku untuk lagu bass yang sedang sejajar dengan melodi dalam interval terts atau sekstet).

e. Dalam susunan SATB, perhatikanlah khususnya suara tenor, karena suara inilah yang menentukan warna dengung. Dalam susunan untuk 
paduan suara SATB, suara tenor boleh bersimpang siur dengan alto.

f. Khususnya jagalah paralel oktaf, kwint, dan prime. Namun, pada tempat yang mau ditonjolkan, pakailah juga sesekali unisono (semua suara digabungkan dalam satu suara).

Berdasarkan buku Arranging and Orchestration oleh Miller (2007:206) chapter 17, Arranging for voice from the limitation of four-voice writing to the necessity of writing lines that can be easily sight-read and sung. that said, let's look at some particular issues and advice most common include, Write for Four (or Fewer) Voices, Vary The Texture, Voice For Effect, and Note-Against-Note vs. Call-andResponse. Di dalam buku bab 17 tersebut, Miller mengatakan bahwa "Arransemen untuk suara/vokal dalam mengatur paduan suara atau empat suara dapat dengan mudah melihat-membaca dan dinyanyikan, serta melihat masalah tertentu, bersama saran/cara umum termasuk: menulis empat (atau sedikit) suara, menggunakan tekstur yang bervariasi, efek suara, dan nada berlawanan dengan cara tanya dan jawab:

a. Write for Four (or Fewer) Voices: Menulis Empat (Atau Sedikit) Suara.

A four-voice choir has four voices. That means no fancy five- and six-part voicings, just simple writing for four (or fewer) voices. That means if you have a fiveor six-note extended chord, you need to pick and choose which notes of the chord get sung. The four-voice limitation also means that you may have to double one or more notes of a standard triad, when you're writing for full ensemble. This isn't that hard, as most voices blend well; it's easy enough to write the women's or men's voices in unison, or to pair the similarly ranged altos with the tenors Miller (2007:207).

Dari kutipan diatas dapat disimpulkan bahwa sebuah paduan suara empat suara memiliki empat suara. Itu berarti tidak ada tambahan lima dan enam-bagian suara, hanya menulis sederhana untuk empat (atau lebih sedikit) suara. Dalam menulis empat suara ada dua kali lipat, satu atau lebih untuk mengatur akord dari triad standar ketika sedang menulis untuk ansambel penuh. Hal ini tidak sulit, karena sebagian besar suara berbaur dengan baik; itu cukup mudah untuk menulis suara perempuan atau suara laki-laki bersama-sama, atau memadukan suara alto dengan tenor.

b. Vary the Texture (Tekstur yang bervariasi)

Another challenge to vocal writing is to avoid falling into the trap of homogenous texture - that is, constant and consistent fourpart writing. If you keep all the voices in a particular range and use similar voicings and voice spacing over an extended series of measures, your piece will start to sound boring. This means you need to vary the number of voices, vary the way voice are used, and vary the voice spacing, the following ways (Miller:2007,207).

1) Vary the number of voices. Don't always use all four voices; let some voices rest so that only three, two, or even a single part is singing at any given time.

2) Vary the way voices are used. Don't have all the voices sing the same rhythm; give the melody to one voice and have the other voices sing sustained-note harmony, or create a rhythmically different countermelody to supplement the main line.

3) Vary the voice spacing. Don't use the same intervals between voices over extended passages. Go for a less homogeneous type of harmony between the voices.

Pada kesimpulan tersebut, tekstur yang bervariasi menjadi cara lain dalam menulis vokal yaitu menghindari jatuh ke dalam bentuk yang sama baik jumlah suara, suara yang digunakan dan jarak suara agar bagian tidak terdengar membosankan. Jadi pada penelitian ini, ketiga variasi dapat digunakan yaitu variasi jumlah suara yang artinya empat suara itu tidak selalu bernyanyi bersamaan, melainkan satu/dua yang menyanyikan. Selanjutnya, variasikan cara suara yang digunakan yang maksudnya bahwa, tidak selalu menggunakan ritem yang sama dan dapat memberikan melodi untuk satu suara/suara tengah yang berirama maupun berbeda. Kemudian, terdapat juga variasi jarak suara yang diperhatikan bahwa jangan menggunakan interval yang sama antar suara lainnya.

c. Voice For Effect (Efek suara). 
When you're experimenting with different voicings and textures, know that certain voice combinations result in some quite interesting vocal effects. Some of the more common voicings and effects include the following (Ketika bereksperimen dengan nada dan tekstur yang berbeda, perlu diketahui bahwa kombinasi suara tertentu dapat menghasilkan beberapa efek vokal cukup menarik. Contohnya adalah sebagai berikut):

1) For a shophisticated, jazzy sound, use close voicing in the middle of a vocal stack (in this instance, between the alto and tenor) for the chord's extended notes, as shown in Figure 2.1 (Untuk efek suara yang memukau, dengan nuansa jazzy, dapat menggunakan interval nada yang berjarak dekat (antara suara alto dan tenor), untuk nada akord yang diperpanjang; seperti yang ditunjukkan pada Gambar 1) (Miller:2007,208).

$\mathrm{s}$

A

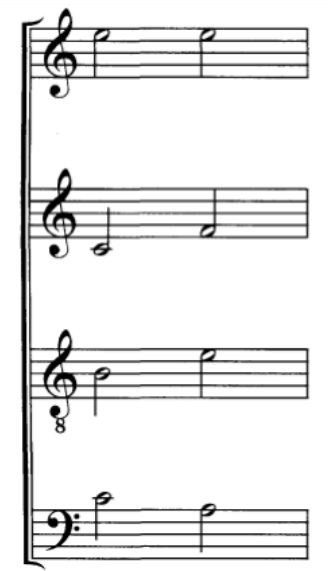

Gambar 1 Extended notes in the middle of a voicing create a jazzy effect. (by: Miller,2007)

2) To create a slightly unsettled sound, use close voicing in the middle of a vocal stack (in this instance, between the alto and tenor) for the chord's extended notes, as shown in Figure 2.2 (Untuk menghasilkan efek suara sedikit gelisah/menggantung, dapat menggunakan interval nada yang berjarak dekat (antara alto dan tenor) untuk nada akord yang diperpanjang; seperti yang ditunjukkan pada Gambar 2.).

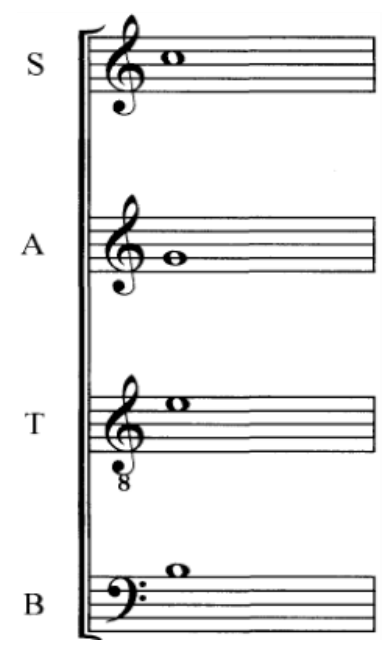

Gambar 2. Extended notes in the bass create an unsettled effect. (by: Miller,2007)

d. Note-Against-Note vs. Call-andResponse.

When writing a two-passage you have a choice to make. You can write the seconde part note-against-note. The first method, creates a more traditional harmony vocal line-either with constant intervals or with a more versatile countermelody. The second approach helps to punctuate the main melody, by repeating or answering key pieces of the melodic phrase (Miller:2007,212). Maksudnya adalah ketika menulis dua bagian kalimat, kita dapat membuat pilihan. Kita dapat menulis bagian dengan note-againstnote. Pada metode yang pertama membuat harmony traditional garis suara dengan interval yang sama atau dengan counter melody. Pada metode kedua menambahkan melodi utama dengan cara mengulangi atau menjawab frase dari melodi utama itu sendiri. Berikut contoh gambar note-against-note vs call-and-a response harmony line:

$\mathrm{S}$

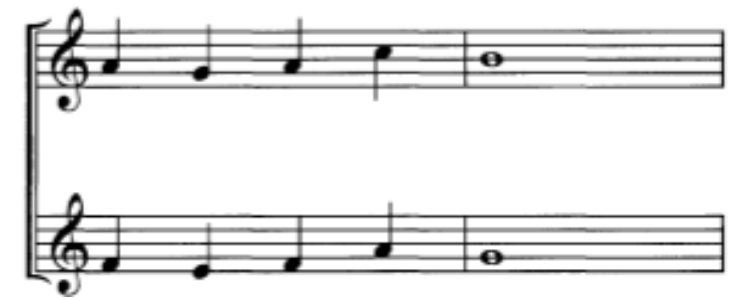

Gambar 3. A note-against-note harmony line (by: Miller,2007) 
$\mathrm{s}$

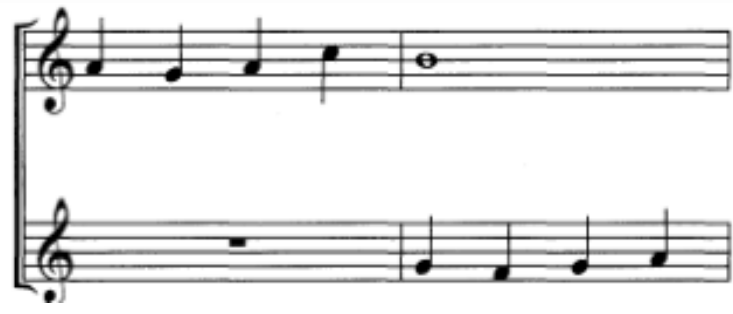

Gambar 4. A call-and-response harmony line (by: Miller,2007)

2. Aransemen Instrumen.

Dalam menyusun aransemen instrumen sangat berbeda dengan aransemen vokal. Untuk menyusun aransemen instrumen, harus menyesuaikan dengan alatalat musik yang dipergunakan. Semakin lengkap alat musik yang dipergunakan, semakin banyak pula kemungkinan variasi yang dapat diciptakan. Untuk menyusun aransemen instrumen, harus berpedoman pada pengetahuan ilmu harmoni dan akord. Bagian-bagian dari suatu aransemen musik dikenal dengan istilah Partituur (Belanda), Partitura (Italia), Part (Inggris), Parte (Perancis). Dalam aransemen instrumen, kebanyakan partitur dimainkan bergantian tugas, sedangkan dalam aransemen vokal pada umumnya semua partitur umumnya berbunyi bersamaan.

3. Aransemen Campuran.

Aransemen campuran adalah campuran aransemen vokal dan instrumen. Teknik yang dilakukan adalah menggabungkan dua jenis aransemen yang telah ada.

Dalam aransemen campuran pada umumnya yang ditonjolkan adalah vokalnya, sedanglan instrumennya berfungsi untuk pengiring dan memeriahkan, sehingga pertunjukan yang disajikan bertambah sempurna. Untuk mengendalikan keseimbangan dalam menampilkan aransemen yang telah disusun, diperlukan adanya seorang pemimpin, yaitu seorang dirigen atau conductor.

\section{Paduan Suara}

Suara merupakan bunyi yang berasal dari pita suara manusia. Masing-masing suara manusia mempunyai perbedaan, mulai dari suara anak-anak, suara orang dewasa lakilaki, maupun suara dewasa perempuan. Akan tetapi, suara dapat dipadukan. Memadukan masing-masing suara tersebut dapat disebut dengan paduan suara. Paduan suara adalah satuan vokal yang dalam berbagai penampilannya dibagi menjadi beberapa jalur suara, masing-masing yaitu: suara sopran, alto tenor, bass (SATB) (Banoe,2003:320).

Wilayah suara manusia berbeda dengan delapan oktaf pada piano, yang dimaksud adalah nada-nada yang masih dapat didengar oleh manusia dalam hubungannya dengan musik, tetapi tidak semua nada tersebut dapat dinyanyikan oleh manusia (bagian yang terlalu rendah dan terlalu tinggi tidak dapat dinyanyikan oleh manusia), karena itu suara manusia mempunyai wilayah nada tertentu, walaupun wilayah ini bukan wilayah mutlak, melainkan wilayah rata-rata bagi jenis suara tertentu.

Pada garis besarnya, suara manusia terbagi menjadi 2 bagian, yaitu (1) Suara wanita, yang meliputi 2 oktaf nada-nada tinggi dan (2) Suara pria, yang meliputi 2 oktaf nada-nada rendah. Oleh karena itu, suara wanita biasa ditulis dengan kunci G, sedangkan suara pria ditulis dengan kunci $F$. Akan tetapi, lebih lengkapnya masingmasing suara terbagi lagi menjadi 3 bagian yaitu:

a. Suara wanita:

1) Tinggi $=$ Sopran (batas wilayah suara dari c1-a2).

2) Sedang = Mezzo Sopran (batas wilayah suara dari a-f2).

3) Rendah = Alto (batas wilayah suara dari f-d2).

b. Suara pria:

1) Tinggi = Tenor (batas wilayah suara dari c-a1).

2) Sedang = Barriton (batas wilayah suara dari a-f1).

3) Rendah = Bass (batas wilayah suara dari f-d1).

Perlu diperhatikan bahwa tinggi suara pria lebih rendah 1 oktaf daripada suara wanita, maka bila penyanyi pria dan wanita bernyanyi, menyanyikan lagu yang terdiri dari satu suara saja, berarti suara pria sebenarnya satu oktaf lebih rendah daripada suara wanita. Oleh karena itu, bila suatu lagu terdiri dari 2 suara, sebenarnya kurang tepat bila dinyanyikan pria dan wanita secara campuran. Akan tetapi keadaan ini dapat diatasi dengan cara: 
1. Suara I dan II masing-masing jenis suara campuran (pria dan wanita).

2. Suara yang rendah (biasanya suara ke II) dinyanyikan oleh wanita, sedangkan suara tinggi (I) dinyanyikan oleh pria.

Dengan demikian seolah-olah tidak ada "kekosongan bunyi" akibat perbedaan yang terlalu jauh antara tinggi suara pria dan wanita.

Selain itu, dalam penelitian ini penulis menerapkan pendekatan musikologi. Musikologi sebagai ilmu pengetahuan, membahas apa dan bagaimana musik secara akademis. Musikologi mengacu pada musik Barat. Jadi teori dan istilah yang digunakan adalah milik Barat. Namun karena hal ini diakui secara internasional, maka Indonesia pun menganut paham musik barat dengan tujuan agar dapat berkomunikasi dengan negara-negara Barat dalam satu bahasa music

Musikologi sebagai seni sudah sangat jelas maksudnya. Bahkan kata seni sering diletakkan di depan kata musik, menjadi seni musik. Lebih dalam lagi orang menyebutnya sebagai seni bermusik yang meliputi bagaimana musik itu diciptakan dan bagaimana seni menciptakan musik. Seni dalam musikologi merupakan perwujudan nyata bahwa sebuah ilmu dapat bernilai dan dianalisis. Dalam musikologi, obyek seninya adalah karakter sebuah kualitas yang selalu bersifat individual, unik, bebas, spontan dan ajaib, penuh pesona, kejutan, sesuatu yang segar dan baru, seolah-olah baru dari ketiadaan (disadur dari staff.uny.ac.id).

\section{PEMBAHASAN}

\section{Karya-Karya Musik Musafir Isfanhari.}

Sebagai tenaga pengajar di Jurusan Pendidikan Sendratasik - Fakultas Bahasa dan Seni - Universitas Negeri Surabaya, Musafir Isfanhari mengampu beberapa mata kuliah, salah satunya adalah mata kuliah Ilmu Harmoni Musik. Pada mata kuliah itu, Isfanhari membagikan materi tentang penyusunan nada-nada suatu lagu dalam format Paduan Suara (Sopran, Alto, Tenor, dan Bass). Dengan membagikan materi Ilmu Harmoni Musik, diharapkan mahasiswamahasiswa kelak mampu mengaransemen lagu dengan tidak hanya mengedepankan unsur estetika atau keindahan suaranya saja, tetapi juga sesuai dengan pakem-pakem atau aturan yang berlaku dalam system penyusunan nada-nada secara harmonis.

Namun, pada kenyataannya, ketika Isfanhari menjalankan tugasnya sebagai seorang arranger, ia tidak pernah menerapkan materi ilmu Harmoni Musik-nya secara mutlak pada saat mengaransemen sebuah lagu. Seperti yang ia kemukakan dalam kutipan wawancara berikut:

Cuma, kalau sudah dalam praktek ya mas ya, mana orang pegang pada teori, gak mungkin dipakai. Teori harmoni itu teori dasar, ketika kita sudah terjun di masyarakat, kayak saya ini, bikin aransemen saya sudah gak mikir teori harmoni, insting saya yang ngomong, naluri saya yang bicara, begini ae begini ae, ini kan melanggar, wes ga peduli. Harmoni kan ada aturannya, kalau akord I ke IV, bassnya dikerjakan dahulu terus yang lain dikerjakan. Itu aturannya begitu, tapi ketika saya sudah nulis di sini, naluri saya mengatakan,

"Sudah, kerjakan sesuai rasamu sendiri". Jadi, ilmu harmoni itu ilmu untuk dasar, ketika dia sudah nulis ya nalurinya yang bicara. Barangkali kalau dianalisa, aransemen saya banyak yang salah juga, menurut apa yang saya ajarkan di unesa. Tapi, perasaan saya mengatakan ini enak kok. (4.W.16:42-52).

Pernyataan ini menunjukkan bahwa Isfanhari menuangkan naluri musisinya saat menggubah lagu. Perpaduan harmoni nadanada terjadi secara natural (alami).

Pada sub-bab ini, dimunculkan 2 (dua) contoh lagu Paduan Suara hasil gubahan Isfanhari, yang kemudian dipaparkan dan dijelaskan secara rinci mengenai perbandingan antara konsep harmoni alami yang digunakan Musafir Isfanhari dengan konsep harmoni sesuai dengan teori musik Barat. Pemaparan ini bukan untuk menunjukkan aransemen mana yang lebih benar, karena pada dasarnya, semua aransemen paduan suara tersebut adalah 
hasil seni manusia, tidak dapat dijatuhkan salah satunya. Konsep harmoni teori musik Barat merupakan konsep dasar yang sudah muncul sejak lampau dan diterapkan di seluruh dunia, sedangkan konsep harmoni musik yang diterapkan oleh Isfanhari muncul atas dasar spontanitas dan naluri keindahan audio Isfanhari secara individu, dengan tetap memperhatikan grand theory dari musik Barat.

Berikut adalah beberapa contoh perbandingan aransemen antara konsep harmoni alami Musafir Isfanhari dengan konsep harmoni musik Barat:

1. Lagu Pop "Diam-Diam Suka":
a.
Konsep Harmon
Alami Musafir Isfanhari:

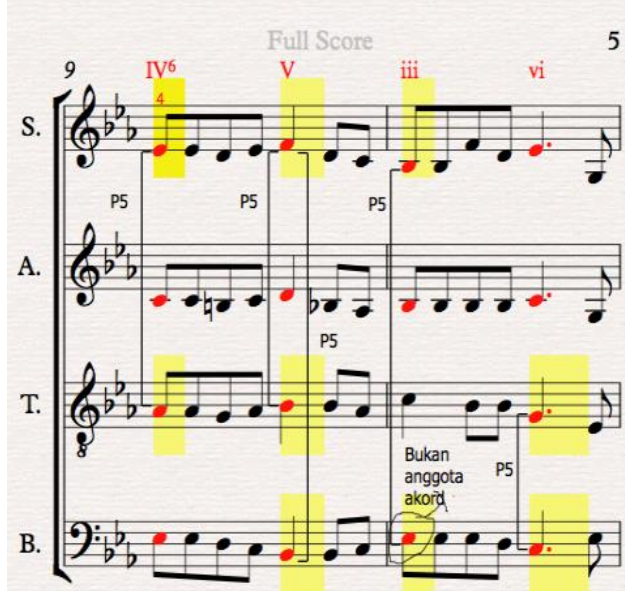

Gambar 5. Contoh penggalan birama lagu pop aransemen Musafir Isfanhari

b. Konsep Harmoni Musik Barat:

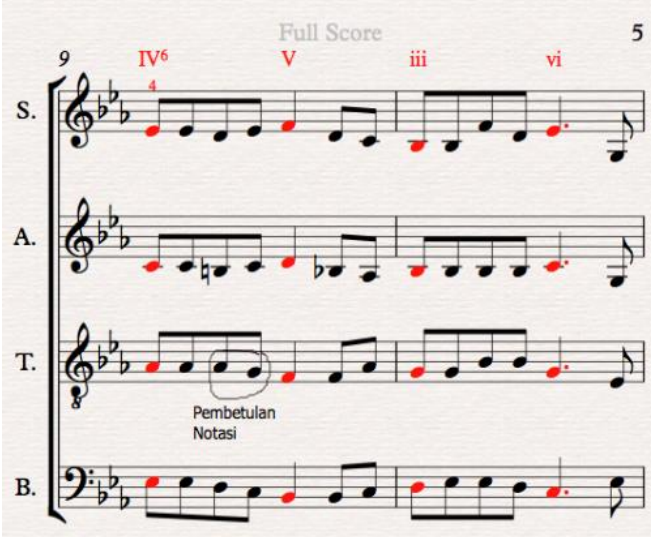

Gambar 6. Contoh penggalan birama lagu pop aransemen dengan konsep music Barat.
2. Lagu Folklore "Semanggi Suroboyo":

a. Konsep Harmoni Alami

Musafir Isfanhari:
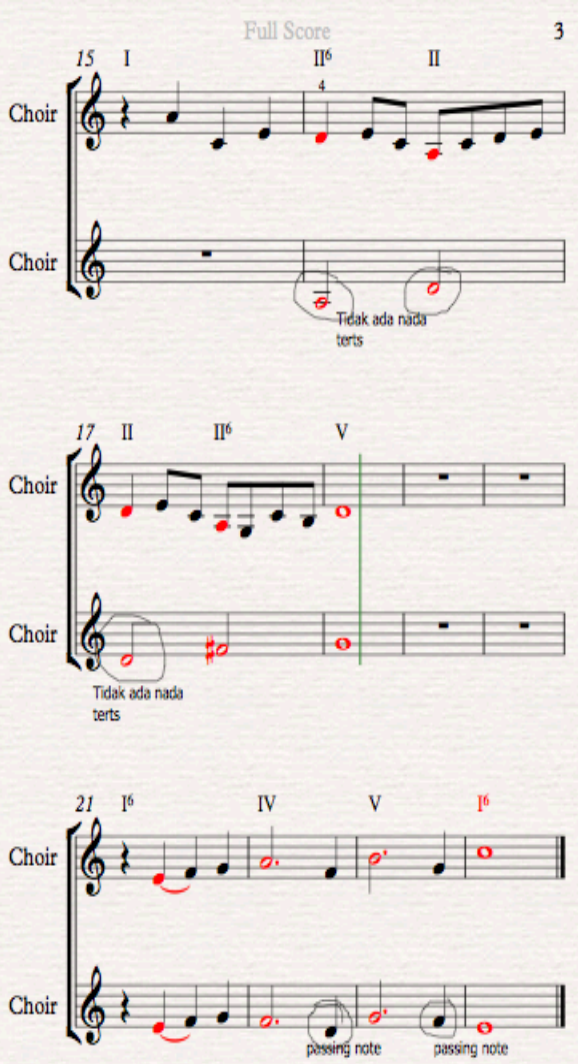

Gambar 7. Contoh penggalan birama lagu folklore aransemen Musafir Isfanhari

b. Konsep Harmoni Musik Barat

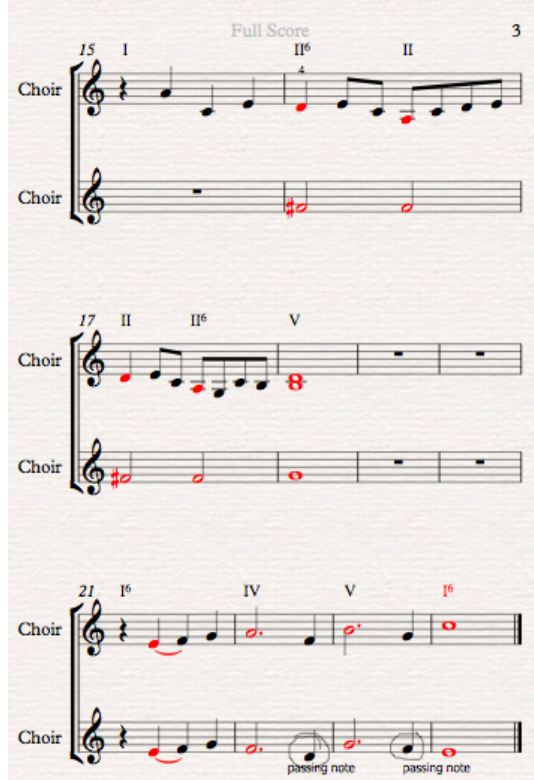

Gambar 8. Contoh penggalan birama lagu folklore aransemen dengan konsep music Barat. 
Penyajian akhir dari analisis aransemen harmoni musik Barat dengan harmoni alami Isfanhari secara garis besar hampir sama. Akan tetapi, apabila diteliti setiap eksekusi notasi yang dipilih, akan nampak perbedaan yang signifikan, di antaranya:

1. Pada harmoni alami yang diterapkan Isfanhari, terdapat banyak interval nada yang membentuk parallel prime (prim ganda), parallel quin (kuin ganda), dan parallel octave (oktaf ganda). Ketiga jenis parallel tersebut tergolong sebagai hal yang dilarang dalam konsep harmoni musik Barat.

2. Selain itu, juga muncul beberapa komposisi nada yang tidak membentuk akor penuh (nada prim, terts, dan kuin), bahkan nada terts banyak yang tidak muncul, padahal standar minimal dalam suatu bentukan akor adalah adanya nada prim dan juga nada terts.

Hal tersebut dapat terjadi karena ketika menggubah sebuah lagu, Isfanhari lebih mengutamakan keindahan secara audio, bagaimana nantinya lagu tersebut akan menjadi bentuk Paduan Suara yang indah didengar, sehingga ia tidak menggunakan konsep harmoni musik Barat secara keseluruhan. Walaupun tidak dipungkiri, ia juga tetap mengikuti aturanaturan dasar yang ada dalam konsep Harmoni musik Barat. Pada akhirnya, dapat dikatakan bahwa kualitas aransemen Paduan Suara (baik yang mengikuti konsep Harmoni musik Barat ataupun yang mengedepankan naluri estetika individu) tidak dapat menjadi suatu ukuran baku, mana yang lebih benar, mana yang lebih indah, karena setiap hasil karya musik akhirnya kembali kepada selera masing-masing pendengar dan juga disesuaikan dengan kebutuhan pada saat itu (siapa yang nantinya akan menyanyikan aransemen tersebut).

\section{KESIMPULAN}

Karya-karya musik Musafir Isfanhari. Aransemen paduan suara yang digarap oleh Isfanhari, baik untuk tujuan komersil maupun untuk tujuan pendidikan, semuanya dikerjakan dengan berdasarkan pada ilmu harmoni. Terdapat beberapa aturan dalam ilmu harmoni yang menjadi dasar dalam mengaransemen suatu lagu. Sebagai pengajar mata kuliah Ilmu Harmoni di Jurusan Sendratasik - Fakultas Bahasa dan Seni Universitas Negeri Surabaya, ternyata Isfanhari tidak secara mutlak menerapkan ilmu tersebut dalam karya aransemennya. Ia mengandalkan naluri musisinya saat mengaransemen. Perpaduan harmoni nadanada terjadi secara naluriah. Isfanhari lebih mengutamakan keindahan secara audio, bagaimana nantinya lagu tersebut akan menjadi bentuk paduan suara yang indah didengar, sehingga ia tidak menggunakan konsep harmoni musik Barat secara keseluruhan. Walaupun tidak dipungkiri, ia juga tetap mengikuti aturan-aturan dasar yang ada dalam konsep Harmoni musik Barat.

\section{DAFTAR PUSTAKA}

Abdurrahman, Dudung. 1999. Metode Penelitian Sejarah. Jakarta: Logos Wacana.

Banoe, Pono. 2003. Kamus Musik. Yogyakarta: Kanisius

Banoe, Pono. 2003.Pengantar Pengetahuan Harmoni. Yogyakarta: Kanisius

Djohan. 2009. Psikologi Musik. Yogyakarta: Best Publisher

Djohan. 2010. Respons Emosi Musikal. Bandung: Lubuk Agung

Fuadi. 2009. "Idris Sardi: Peranannya dalam Perkembangan Musik di Indonesia". Tesis Tidak Diterbitkan. Yogyakarta: Universitas Gajah Mada

Gottschalk, Louis. 1986. Mengerti Sejarah: Pengantar Metode Sejarah (Penerjemah: Nugroho Notosusanto). Jakarta: Penerbit Universitas Indonesia Hauser, Arnold. 1982. The Sociology of Art. United States of America: The University of Chicago Press

Jamalus, Drs. 1988. Pengajaran Musik Melalui Pengalaman Musik. Jakarta: Direktorat Jenderal Pendidikan Tinggi Departemen Pendidikan dan Kebudayaan

Kuntowijoyo, 2003. Metodologi Sejarah. Jakarta: Tiara Wacana

Muttaqin, dkk. 2008. Seni Musik Klasik untuk Sekolah Menengah Kejuruan. Jakarta: Penerbit BSE 
Pradhita, I Putu Candra. 2015. "I Wayan Dibia: Pencipta dan Pemikir Seni Tari di Bali". Tesis Tidak Diterbitkan. Surabaya: Universitas Negeri Surabaya

Prier, Karl-Edmund. 1991. Ilmu Bentuk Musik. Yogyakarta: Pusat Musik Liturgi

Prier, Karl-Edmund. 2009. Ilmu HarmoniEdisi Baru. Yogyakarta: Pusat Musik Liturgi

Prier, Karl-Edmund. 2011. Kamus Musik. Yogyakarta: Pusat Musik Liturgi

Prier, Karl-Edmund. 1993. Sejarah Musik Jilid 2. Yogyakarta: Pusat Musik Liturgi

Silalahi, U. 2009. Metode Penelitian Sosial. Bandung: Penerbit Refika Aditama

Simanungkalit, M. 2008. Teknik Vokal Paduan Suara. Jakarta: PT Gramedia Pustaka Utama

Sjamsuddin, Helius. 2007. Metodologi Sejarah. Jakarta: Penerbit Ombak

Sugiyono, 2009. Memahami Penelitian Kualitatif. Bandung: Penerbit Alfabeta

Sugiyono. 2014. Metode Penelitian Kuantitatif, Kualitatif, dan $R \& D$. Bandung: Penerbit Alfabeta

Sulasman. 2014. Metodologi Penelitian Sejarah. Bandung: Pustaka Setia

Swaratyagita, Gema. 2012. Konsep Minimax Slamet Abdul Sjukur dalam Pembelajaran Komposisi Musik di Perguruan Tinggi. Tesis Tidak Diterbitkan. Surabaya: Universitas Negeri Surabaya

Sztompka. Piotr. 2007. Sosiologi Perubahan Sosial. Jakarta: Penerbit Prenada

Tim Redaksi. 2005 . Kamus Besar Bahasa Indonesia. Jakarta : Balai Pustaka

Pasaribu, Rianti Magdalena. 2012. "Biografi Karl-Edmund Prier: Perjalanan Hidup dan Karya-Karyanya”. Tesis Tidak Diterbitkan. Yogyakarta: Universitas Gajah Mada 